\title{
REPRESENTAÇÕES DE SI NOS DISCURSOS FEMINISTAS EM PRÁTICAS MIDIÁTICAS DIGITAIS COLETIVAS: NÃO ME KAHLO E AZMINA
}

\author{
NAYARA IRIS SILVA E SOUZA ${ }^{1}$ \\ PAULO HENRIQUE AGUIAR MENDES ${ }^{2}$
}

\begin{abstract}
Universidade Federal de Ouro Preto
Programa de Pós-Graduação em Letras - Estudos da Linguagem, Instituto de Ciências Humanas e Sociais - ICHS, Rua do Seminário, s/n, 35400-000 Mariana (MG) - Brasil
\end{abstract}

nayara iris@hotmail.com, pauloufop01@gmail.com

\begin{abstract}
Resumo. A presente pesquisa busca compreender como os grupos de mulheres feministas e militantes constroem espaços de resistência na mídia on-line. Em especial, buscamos identificar e analisar as estratégias discursivas que colaboram para a construção do ethos da mulher contemporânea como resistência política. Este artigo analisa dois ambientes de representatividade coletiva: um blog Não me Kahlo e uma Revista on-line, AzMina. Por meio da Análise do Discurso, buscamos compreender como a mídia on-line, como plataforma de propagação do discurso, auxilia na construção de novas realidades, neste caso a identidade e a imagem da mulher e do feminino.
\end{abstract}

Palavras-chave: Análise do discurso; Ethos Discursivo; Midias Digitais; Feminismo.

\begin{abstract}
The present research seeks to understand how groups of feminist and militant women construe spaces of resistance on online media. Specially, our objectives are to identify and to analyze the discursive strategies that contribute to construing the contemporary woman's ethos as political resistance. This article analyzes two environments of collective representativeness, namely a blog, Não me Kahlo, and an online magazine, Az-Mina. Through Discourse Analysis, we sought to understand how online media as a platform for discourse propagation assists in the construction of new realities, in this case, identity and image of women and the feminine.
\end{abstract}

Keywords: Discourse Analysis; Discursive Ethos; Digital Media; Feminism.

\footnotetext{
${ }^{1}$ Mestra em Estudos da Linguagem pela Universidade Federal de Ouro Preto (UFOP).

${ }^{2}$ Doutorado em Estudos Linguísticos pela Universidade Federal de Minas Gerais (1999). Professor Adjunto

IV da Universidade Federal de Ouro Preto (UFOP).
} 


\section{INTRODUÇÃO}

Esta pesquisa ${ }^{3}$ tem como base a emergência de novas reflexões acerca das desigualdades originadas das relações assimétricas de poder em sociedade. $\mathrm{Na}$ modernidade recente, um dos meios utilizados pelos grupos de maior vulnerabilidade para que suas vozes sejam ouvidas tem sido a mídia alternativa. Com o advento da internet, diversas plataformas on-line asseguram a liberdade de expressão, permitindo que estes grupos tenham espaço para se expressar, seja através do Facebook, blogs, twitter, revistas e jornais on-line ou plataformas de vídeos como Youtube.

As plataformas de comunicação on-line tornaram-se instrumentos de luta, pois fornecem espaço para construção de um novo discurso, ou, como chamaremos aqui, contradiscurso, que mobiliza estratégias enunciativas para combater e resistir aos discursos hegemônicos propagados (que ali também se encontram presentes). Cristiane Dias (2019, p. 133) afirma que "é pela circulação (compartilhamento, viralização, comentários, postagens, hashtags, memes, links...) que o discurso digital se formula e se constitui". A mídia, como prática discursiva, configura-se, portanto, como uma possibilidade de fomentar a igualdade.

Em outros termos, a emergência de vozes portadoras de mídias, em função da possibilidade de uma circulação descentralizada dos discursos, o que se dá pela reapropriação social dos dispositivos tecnológicos e das plataformas digitais, e implica necessariamente uma deriva de seus usos. Metaforização do sujeito com a mídia e do sujeito com a linguagem. É desse modo que dizemos que a forma de circulação de um dizer tem efeitos sobre sua formulação e sobre a constituição dos sujeitos em sociedade. (DIAS, 2019, p.132)

Esta pesquisa dedica espaço às vozes feministas, reconhecendo-as como grupo de minorias. O termo "minorias" é compreendido não por sua dimensão numérica, mas por se encontrar em desvantagem ou em posição de subordinação na relação de dominação na maneira como a sociedade se organiza em grupos (por motivos religiosos, preferência sexual, gênero, etnia etc.). Em um sentido mais amplo, Mendes Chaves (1970, p. 149) aponta como minorias

Um grupo de pessoas que de algum modo e em algum setor das relações sociais se encontra numa situação de dependência ou desvantagem em relação a um outro grupo, "maioritário", ambos integrando uma sociedade mais ampla. As minorias recebem quase sempre um tratamento discriminatório por parte da maioria.

O movimento feminista tem buscado estratégias para desestabilizar a estrutura social dominante/hegemônica, pautada nos valores do patriarcado, resultando na supremacia masculina e na inferiorização da mulher, e se identifica como um movimento social que busca a igualdade de gênero na sociedade. O uso do termo "movimento social" justifica-se por acreditarmos que a parcela da sociedade em situação de vulnerabilidade se organiza em grupos, os quais se identificam, discutem e lançam luz a temas que são

\footnotetext{
${ }^{3}$ Esta pesquisa foi fruto da minha dissertação de mestrado apresentada ao Programa de Pós-Graduação em Letras: Estudos da Linguagem, do Instituto de Ciências Humanas e Sociais da Universidade Federal de Ouro Preto.
} 
considerados relevantes para a equidade social. Neste sentido, a dominação é sustentada por meio da ideologia. Entendemos ideologia como "um instrumento de dominação de classe porque a classe dominante faz com que suas ideias passem a ser ideias de todos" (BRANDÃO, 2014, p. 21). As ideologias tornam-se hegemônicas quando alcançam um grau de estabilidade que as faz parecer essenciais, naturais, óbvias e imutáveis. Estas se tornam sedimentadas no pensamento cotidiano, de modo a parecer que sempre estiveram ali. Nesse ponto, elas se tornam senso comum, pois estão presentes desde a formação das estruturas da sociedade, são enraizadas através da cultura, da religião e das instituições dominantes.

Diante desse cenário, como alterar a estrutura social dominante? Há possibilidade de mudança? O patriarcado e o machismo podem ser rompidos? Sim. "A capacidade do ser humano de transformação ou contestação de hegemonias e ideologias, de mudança social e discursiva, depende da reflexividade e da agência das pessoas" (SOUZA, 2017, p. 15). As hegemonias estão num constante processo de reafirmação de si mesmas, o qual é interceptado pela possibilidade de agência, que são variáveis. O conceito de agência foi cunhado por Giddens (2003) e significa a possibilidade de inovar. Para o autor, ser agente é ter a capacidade de agir de modo diferente do usual, se reelaborando e transformando o que parecia ser imutável, essencial, hegemônico.

As mídias digitais proporcionam grande alcance e visibilidade aos debates atuais, de modo que a circulação das ideias e a articulação de grupos pertencentes a movimentos como o feminismo cresceram visivelmente. A luta hegemônica, que antes acontecia localmente, tornou-se global e a busca por mudança social e pela distribuição igualitária de poder deixou de acontecer isoladamente e passou a ser um ato contestatório reconhecido.

Pretendemos identificar e analisar as estratégias discursivas que colaboram para a construção do ethos da mulher contemporânea como resistência política, na busca de igualdade de gênero na sociedade, para modificar uma estrutura social enrijecida, ou seja, como esse espaço de luta é concebido nos veículos midiáticos on-line. Os objetos discursivos que compõem essa pesquisa são 01 (um) blog, Não me KAHLO e 01 (uma) revista on-line, AzMina.

\section{ESTUDOS DA LINGUAGEM}

Devemos ter sempre em conta que as questões sociais são também questões que permeiam o discurso. É preciso considerar que os locutores dos discursos escolhidos para compor o corpus dessa pesquisa agem de acordo com a situação social na qual estão inseridos e conforme os papéis sociais que estão representando no momento da enunciação. De alguma forma, todos esses locutores imaginam um alocutário para suas falas, seja individual ou coletivamente, de forma consciente ou inconscientemente, pois o discurso sempre pressupõe o outro.

Como elemento de mediação necessária entre o homem e sua realidade e como forma de engajá-lo na própria realidade, a linguagem é lugar de conflito, de confronto ideológico, não podendo ser estudada fora da sociedade, uma vez que os processos que a constituem são histórico- 
sociais. Seu estudo não pode estar desvinculado de suas condições de produção. (BRANDÃO, 2014, p. 11)

As relações desiguais de poder existentes no interior das interações sociais são produzidas por meio da linguagem e reproduzidas, também, pela linguagem. Reconhecemos, nesta pesquisa, a ideia de discurso como o uso dialógico da linguagem para produzir sentido, o que pode construir e modificar as ações e as estruturas de uma sociedade. O discurso não deve ser visto como algo acabado e imutável, pois é um fenômeno intertextualmente orientado, o que nos leva a crer que é constituído de outros dizeres, outros discursos, em outras situações de enunciação. No momento da enunciação, a linguagem é posta em ação em função de todo o contexto que diz respeito às condições de produção discursiva. Assim, alguns fatores são essenciais para a realização da enunciação, e toda enunciação contém os elementos primeiros que são locutor, alocutário e referência.

Toda enunciação se processa em uma situação de interação social concreta, cujos interlocutores assumem determinadas identidades e objetivos discursivos, compartilham certos universos referenciais e dominam um conjunto de regras constitutivas das práticas de linguagem em que se inserem. Assim, a Análise do Discurso busca compreender as relações entre os enunciados e as suas condições de produção/interpretação, pois entende que os signos por si só não têm sentido discursivo.

O fenômeno da enunciação implica realizar ações por meio do discurso, que podem funcionar como forma utilizada pelo locutor para convencimento do outro, uma maneira de demonstrar poder e ação sobre o interlocutor. O controle do discurso se aplica em todas as camadas e nas mais diversas áreas. Não somos livres para fazer, pensar ou agir do modo que queremos, pois são as instituições como mídia, escola, a polícia, a igreja, etc. que controlam nossos discursos de acordo com o interesse que detêm. Esse poder, chamado de poder simbólico ${ }^{4}$, é adquirido através do acesso concedido pelas instituições ao discurso público.

Cada gênero discursivo tem condições de produção específicas e determinada pessoa é, em cada situação de enunciação, legitimada a proferi-la. Com base na teoria Semiolinguística do Discurso, Charaudeau (2016) apresenta o que considera como 03 (três) elementos necessários para que se tenha poder: legitimidade, autoridade e potência. A legitimidade define quem está autorizado a falar, se faz necessário ser legitimado pela sociedade a ocupar determinadas posições enquanto sujeitos discursivos, essa legitimidade é conferida através do outro, que reconhece o sujeito e lhe confere poder. Por meio dela que é conferida potência e autoridade.

A imagem que o sujeito constrói de si no momento da interação discursiva é a apresentação de si que, por sua vez, pode ser formada pela oratória, os gestos, a corporalidade etc. $\mathrm{O}$ orador tem necessidade de "se adaptar a seu auditório, portanto, de fazer uma imagem dele e, correlativamente, de construir uma imagem confiável de sua própria pessoa, em função das crenças e valores que ele atribui àqueles que o ouvem." (AMOSSY, 2018, p. 19). Charaudeau (2013) entende o ser de palavra como um ser duplo,

\footnotetext{
${ }^{4}$ Ver: BOURDIEU, Pierre. O poder simbólico. Trad. Fernando Tomaz. Rio de Janeiro: Bertrand Brasil. 1989.
} 
que é construído com base no seu discurso e na legitimidade de ser social, essas identidades discursivas e sociais fusionam no ethos.

Essa imagem discursiva pode não ter correspondência com o indivíduo enquanto ser social, ela depende da intenção do orador no discurso. O ethos é, então, essa imagem construída no discurso, é "o resultado de uma encenação sociolinguageira que depende dos julgamentos cruzados que os indivíduos de um grupo social fazem uns dos outros ao agirem e falarem.” (CHARAUDEAU, 2013, p. 118)

A atividade da argumentação objetiva, em linhas gerais, produzir o efeito de persuasão. Desde Aristóteles, as provas retóricas se traduzem pelas categorias do ethos, do pathos e do logos, as quais se relacionam de forma integrada nas práticas discursivas. A dimensão do ethos está relacionada à imagem do orador; a dimensão do pathos se refere às emoções e afetos projetados no auditório, enquanto a dimensão do logos diz respeito à racionalidade dos argumentos constitutivos do próprio discurso. O orador, ao dizer algo, projeta uma imagem de si, que é considerada o seu ethos. No entanto, para que a legitimidade do orador seja validada pela sua credibilidade, é necessário que o auditório a reconheça por meio do discurso.

Compreendemos a Análise do Discurso como um campo de estudos que pode contribuir para as questões que envolvem o feminismo, situadas em meios digitais, posto que esse ambiente tem se tornado local de debates e resistência a discursos dominantes, "o espaço virtual tem sido um espaço de disputas de narrativas, pessoas de grupos historicamente discriminados encontram aí um lugar de existir" (RIBEIRO, 2017, p. 86). As novas mídias permitiram que novas vozes fossem ouvidas, ou, pelo menos, estabeleceram um lugar de fala para essas vozes que não podiam se manifestar. A liberdade que as mídias proporcionam trazem à tona a pluralidade de ideias; afinal há espaço para grupos que são, por diversas razões, discriminados na sociedade.

\section{O FEMINISMO E OS MOVIMENTOS SOCIAIS EM REDE}

A emergência do movimento feminista ventilou a reflexão sobre a desigualdade implícita nos papéis de gênero socialmente impostos. O feminismo está centrado na necessidade de pensarmos o patriarcado como uma estrutura que se perpetua e propaga a imposição de papeis definidos de maneira essencial e naturalizada, como se fôssemos seres fixos, rígidos, e houvesse uma forma única de performatividade das identidades de gênero. "O feminismo questionou a distinção entre dentro-fora, público-privado e abriu para contestação política arenas da vida social como família, sexualidade, trabalho doméstico." (CASTRO e PRADO, 2012, p. 247)

Essa diferença sexual estabelecida historicamente se justifica pelo fato de que "quando duas categorias humanas se acham presentes, cada uma delas quer impor à outra sua soberania" (BEAUVOIR, 2016, vol. 01, p. 95). Uma forma encontrada pelos homens, por exemplo, de se tornarem superiores foi privar às mulheres o acesso à educação, as quais, durante muito tempo, não puderam recebê-la. A situação de igualdade deve existir nas relações econômicas, trabalhistas, jurídicas e familiares. É necessário combater esse persistente desequilíbrio que proporciona uma relação de superioridade e inferioridade entre os sujeitos. 
No cenário recente, segundo a Organização das Nações Unidas (ONU), o salário atual da mulher é em média $24 \%$ inferior ao do homem. No que tange ao espaço no mercado de trabalho, mesmo aquelas que o conquistaram, têm a chamada "dupla jornada", que é o cuidado do lar e a responsabilidade pelos filhos. Se trabalham fora de casa, na maioria dos casos, o trabalho doméstico continua sendo sua responsabilidade, não é compartilhado e nem remunerado. Se considerarmos a desigualdade racial, a discrepância dos dados é ainda maior, pois as mulheres são duplamente discriminadas e esses fatos refletem profundamente no estilo de vida delas. Ser branco ou negro determina o espaço social de cada um, bem como o espaço de fala. Se pensarmos na "linguagem como mecanismo de manutenção de poder" (RIBEIRO, 2017, p. 14), compreendemos a importância da presença de mulheres negras nos meios políticos, espaços esses que são decisórios no momento de tomadas de decisões. No entanto,

Segundo pesquisa desenvolvida pelo Ministério do Trabalho e Previdência Social em parceria com o Instituto de Pesquisa Econômica Aplicada (IPEA), de 2016, 39,6\% das mulheres negras estão inseridas em relações precárias de trabalho, seguidas pelos homens negros $(31,6 \%)$, mulheres brancas $(26,9 \%)$ e homens brancos $(20,6 \%)$. Ainda segundo a pesquisa, mulheres negras eram o maior contingente de pessoas desempregadas e no trabalho doméstico. (RIBEIRO, 2017, p. 40).

Além disso, o feminismo passou a questionar a universalização da categoria mulher, levantou debate para discutir as várias intersecções que permeiam o ser mulher como raça e identidade de gênero. Até hoje, os padrões esteticamente estabelecidos, padrões de beleza racistas, paradigmas impostos, o preconceito racial e de gênero são os temas mais debatidos no interior dos movimentos. A sociedade percebe o corpo da mulher como objeto a ser consumido. Além de serem padrões sexistas, são racistas, pois o grupo oprimido não se vê representado, e nesse caso, há apagamento e desvalorização das mulheres nestas identidades construídas.

Os meios digitais propiciam espaço de debate para mulheres, negros, pessoas em situação de rua, indígenas, ciganos, entre outros grupos que se sentem oprimidos e sem lugar de fala nos ambientes de privilégio, como as instituições. Logo, os suportes de comunicação têm grande influência nos processos de construção de novas formas de relações sociais. Os "movimentos sociais em rede" (CASTELLS, 2017) têm sua importância cada vez mais reconhecida como uma das principais formas de construção de posicionamentos identitários, inclusive em termos de manifestação de insatisfação por grande parte da sociedade. Um dos principais fatores que colaboram para maior efervescência desses movimentos é a indignação social. "Embora esses movimentos geralmente se iniciem nas redes sociais da internet, eles se tornam um movimento ao ocupar o espaço urbano, seja por ocupação permanente de praças públicas, seja pela persistência das manifestações de rua" (CASTELLS, 2017, p. 192, grifo do autor).

A rede on-line tornou-se um essencial meio de denunciar diferentes formas de opressão (vividas pelas minorias), tornando a interação entre os interlocutores mais ágil e proporcionando um meio de organização dos discursos alternativos que têm a mesma identidade - "A empatia no processo de comunicação é determinada por experiências semelhantes às que motivaram o acesso emocional inicial". (CASTELLS, 2017, p. 29) Aproximamos ou afastamos de certos grupos de acordo com nossas preferências, gostos, 
estilos ou crenças, que se desenvolvem em contato com o ambiente coletivo, proporcionando uma pluralidade de identidades.

O que confere força a um movimento social, muitas vezes, está ligado aos aspectos relacionados à emoção, que faz com que os indivíduos se liguem entre si através da comunicação. Quando isso ocorre, é que nos identificamos ou nos sentimos inseridos como pertencentes àquela determinada classe social, grupo ou categoria. Os suportes de comunicação (eletrônico ou impresso) têm grande influência nos processos de construção de novas formas de relações sociais.

O desenvolvimento dos meios de comunicação trouxe profundas transformações no modo como os sujeitos entendem as relações sociais e com isso transformou a natureza da produção e circulação das formas simbólicas - expressões linguísticas, gestos, ações, obras de arte, etc. no mundo moderno. Segundo Thompson (1995), os meios de comunicação e a mídia em si criam novas formas de ação e interação entre os indivíduos e novos tipos de relações sociais. (CASTRO e PRADO, 2012, p. 241 e 242)

A rede on-line permite que milhares de pessoas se conectem por um mesmo vínculo, o que faz com que se espalhem muito rapidamente os dados ou discursos presentes no ambiente virtual.

\section{METODOLOGIA DE PESQUISA}

Os objetos discursivos que fazem parte do corpus que compõe essa pesquisa apresentam como lugares de origem 01 (um) blog, Não me KAHLO ${ }^{5}$ e 01 (uma) revista on-line, AzMina ${ }^{6}$. A escolha metodológica se deu por serem instrumentos considerados plataformas de largo alcance midiático, além de apresentarem diferentes gêneros textuais, entendendo que esta diversidade auxilia no reconhecimento da heterogeneidade do perfil feminino. Esta pesquisa é de cunho qualitativo e documental, visto que a análise se baseia puramente em textos.

A escolha do blog e da revista on-line se justifica pela representatividade coletiva desses perfis, entendendo que esse tipo de plataforma não é realizado por um sujeito único, mas por um conjunto que, no ambiente virtual, é conhecido como “colaboradores/as". O blog Não me Kahlo conta com 1.232.701 (um milhão, duzentos e trinta e dois mil, setecentos e um) de seguidores em sua página de Facebook e apresenta um total de 66 postagens no período de 01 de julho a 31 de dezembro de 2017. Em relação à revista on-line AzMina, no período analisado, houve 67 postagens e a plataforma contém 129.743 (cento e vinte e nove mil, setecentos e quarenta e três) seguidores.

Optamos por separar as análises por tópicos que salientam as transversalidades. As perguntas que norteiam essa pesquisa são: Por meio de quais estratégias discursivas se constrói a representatividade feminina nos veículos midiáticos on-line? Qual o ethos

\footnotetext{
${ }^{5}<$ https://www.naomekahlo.com/>

${ }^{6}<$ https://azmina.com.br/>
} 
da mulher contemporânea como resistência política? Como se concebe o espaço da luta feminista nas estratégias discursivas analisadas?

\section{AS IMAGENS DOS AMBIENTES COLETIVOS MIDIÁTICOS ON-LINE, Não me Kahlo E AzMina}

O ethos pré-discursivo do blog Não me Kahlo é construído a partir da intertextualidade com o nome da artista mexicana Frida Kahlo, além de remeter à questão do silenciamento, a que durante muitos anos as mulheres foram submetidas. Assim como o blog, a revista on-line AzMina, feita para mulheres de A a Z, faz referência à heterogeneidade de mulheres, que propõem uma plataforma que possa discutir e debater narrativas desses diferentes perfis. Além do mais, a expressão "mina" é uma forma reduzida de "menina", muito utilizada na linguagem informal para se referir à mulher.

Nas análises, dois ethé se destacaram como predominantes: ethos de credibilidade e de identificação e, dessa forma, dividimos o capítulo, para melhor compreensão por parte do leitor.

\section{ETHOS DE CREDIBILIDADE}

A princípio, é importante notar que alguns aspectos gerais se destacaram nas análises. As mídias funcionam como meios de propagação de livros, teatro, música, filmes, exposições culturais que são realizadas por mulheres ou que falam sobre elas. Esses eventos têm a função de manter as mulheres informadas sobre acontecimentos do âmbito social, que podem contribuir para uma formação mais consciente, que enriquecem culturalmente e ampliam o conhecimento dessas mulheres.

Outra estratégia recorrente na plataforma digital é o uso de fatos que comprovam o ponto de vista das autoras conferindo o ethos de credibilidade aos seus textos e, consequentemente, reafirmando seus argumentos acerca dos temas abordados. Além disso, quando usam termos que o/a leitor/a pode desconhecer, elas optam por trazê-los acompanhados da explicação. Essa preferência auxilia a compreensão dos artigos postados, e torna o texto mais acessível a todos/as, empoderando essas mulheres.

1) Bifobia é o nome que se dá a formas de violência, preconceito e discriminação direcionadas a pessoas bissexuais. (LEÃO, Bruna. Bissexualidade não é doença, Não me Kahlo, 23 de setembro de 2017).

$\mathrm{O}$ uso de alguns termos pode ser incomum à grande maioria das mulheres. $\mathrm{Na}$ prática elas vivenciam e reconhecem o significado dessas expressões, mas, à primeira vista, os termos parecem-lhes desconhecidos e impedem a adequada compreensão daquele discurso pretendido. Esse/a autor/a que prevê a possível dificuldade por parte do/a leitor/a, projeta uma imagem que resulta no ethos de competência, pois reconhece a necessidade de alcançar a/o outra/o (o interlocutor) em seu discurso, conferindo-lhe saber e conhecimento.

Em algumas publicações há presença de parágrafos e, até mesmo, seções que foram dedicadas a contextualizar ou esclarecer a temática que se propôs a debater. Os 
canais de comunicação analisados se preocupam em transmitir a informação completa ao público. Para esse fim, algumas publicações, que explanam sobre certos debates e temáticas, dedicaram-se a explicar a respeito do que se pretende abordar.

2) Segundo leite (2003) a imprensa feminista foi inserida nos anos de 1970 na imprensa democrática, alternativa ou na imprensa nanica. Os jornais tinham formato de tabloides, com tiragem irregular e venda majoritária dentro da militância, apesar de também serem vendidos nas bancas. (...) (DANTAS, Heloisa. Mulherio: a imprensa feminista na ditadura militar, Não me Kahlo, 11 de setembro de 2017).

O blog apresenta um panorama de antes e agora para o/a leitor/a, inserindo a dimensão da historicidade nos artigos que lhe cabem, como no exemplo acima, em que a autora procura contextualizar o/a leitor/a sobre as características da imprensa feminina no início. Ademais, os ambientes on-line, ao mesmo tempo em que se propõem a informar, possibilitando conhecimento, propiciam espaço para trocas de informações buscando interagir diretamente com os interlocutores.

3) Ficou com alguma dúvida? Quer saber sobre algo específico? É só mandar a pergunta que a gente responde! (MUND, Sarah. Mulher, negra, trans: a vida real é uma somatória de opressões, AzMina, 04 de julho de 2017).

Além do excerto acima, as autoras em suas demais postagens convidam aqueles/as que possam ter mais informações a contribuírem ou corrigi-las se necessário, demonstrando, assim, que elas não se sentem detentoras de todo conhecimento, mas são receptivas à colaboração dos/as leitores/as e entendem que essas colaborações são de grande valia para que esse conhecimento se propague ainda mais, resultando em uma relação recíproca de credibilidade entre leitor e escritor.

As mídias digitais conferem uma "licença" que permite aos/às escritores/as se manifestarem da maneira que se sentem mais confortáveis e preparados/as. Essa é uma das estratégias das plataformas que objetivam buscar proximidade com o/a leitor/a ao fazer uso de expressões e linguagem que não são, exclusivamente, do meio acadêmico, mas presentes no nosso dia a dia e de fácil compreensão para leitores/as dos mais diferenciados graus de escolaridade. Há uma gama de textos em que se destaca o uso da primeira pessoa, o comportamento elocutivo é característica recorrente, uma vez que a maioria são relatos de experiências dessas mulheres.

4) Eu fui recentemente entrevistada pelo New York Times a respeito do meu trabalho e meus escritos como uma feminista trans. (...) (SERANO, Julia. Desconstruindo os argumentos de que "mulheres-trans-não-são-mulheres", Não me Kahlo, 02 de agosto de 2017, grifo nosso).

O fato de essas vozes poderem emergir em meio a uma cultura de silenciamento, em especial no caso das mulheres negras, é carregado de significados, resultado da visibilidade que elas adquirem, deixando de ser indivíduos silenciados, tornando-se seres políticos. Percebemos que hoje elas encontram espaço para se colocar, existir no meio intelectual, divulgar seus trabalhos, obras, pesquisas etc. Ainda assim, este espaço não é igualitário. 
Nesse sentido, a presença da escrita acadêmica demonstra que elas estão preparadas tanto para escrever quanto para ler uma forma de linguagem mais complexa e elaborada, resultando no ethos de competência; exprime também que estão cada vez mais interessadas em dar continuidade à educação. A presença das duas linguagens, formal e informal, é democrática, afinal se tornam canais de comunicação, acessíveis às pessoas de diferentes graus de escolaridade.

Além disso, não há somente exposição de fatos, mas reflexões que podem vir a contribuir para conscientização e, consequentemente, vir a mudar a realidade dos/as leitores/as.

5) Se eu não leio mulheres, como vou pensar fora da caixa do machismo? Se eu não leio mulheres negras, como vou pensar fora do racismo estrutural, como vou pensar para além do patriarcado? Se eu não leio pesssoas trans, como vou pensar fora da camisa-de-força do binômio de gênero? Perguntas que nem sempre a crítica, editoras, prêmios literários e debates públicos estão preparados para responder. (ESCALEIRA, Bruna. Mulheres na literatura: a 'força bruxa' emerge para quebrar a hegemonia masculina, AzMina, 22 de agosto de 2017, grifo da autora).

A experiência é característica fundamental para construção dos textos. As escritoras trazem exemplificações de histórias reais para dentro de seus artigos e apresentam outras possibilidades com o objetivo de refletir nas dificuldades que cada interlocutor possa estar passando. Nos enunciados analisados, a opinião do blog, bem como das autoras, é apresentada de maneira explícita, elas se sentem à vontade para expressar seus pontos de vista.

Por fim, outro elemento nos sítios virtuais é o fato das postagens serem frutos de longas pesquisas. Os/as autores/as utilizam estratégias discursivas como informações científicas, discurso de autoridade e resultados de pesquisas a fim de construir uma esfera de credibilidade diante de seu auditório. Observe:

6) José* foi o primeiro de muitos motoristas que ouvimos para produzir esta série. Como a maioria de seus colegas, depois de tantos anos na estrada testemunhando cenas de exploração sexual, acabou se acostumando a vivenciá-las. (...) De acordo com o mapeamento, os 1104 pontos críticos e de alto risco estão em 470 municípios brasileiros. Mais de $90 \%$ desses municípios possuem o IDHM (índice que mede longevidade, educação e renda municipal) médio ou muito baixo (ou seja, entre 0,00 e 0,699). (AZMINA, As meninas de Minas, 11 de dezembro de 2017, grifo nosso).

Esses aspectos resultam na construção do ethos de credibilidade das postagens, além de apresentar a seriedade e competência das páginas que buscam debater temáticas do âmbito dos estudos feministas. Entretanto, além de se utilizarem de estratégias discursivas que colaboram para criação da imagem de credibilidade das páginas analisadas, buscando trazer informação e conhecimento aos seus/suas interlocutores/as, as plataformas buscam ser locais de posicionamento identitário. Na próxima seção desta pesquisa, optamos por discutir o que Charaudeau (2013) classifica como ethos de identificação. 


\section{ETHOS DE IDENTIFICAÇÃO}

Como em grande parte dos textos os/as autores/as discorrem sobre experiências pessoais, ou fazem uso de exemplificações de posições identitárias para construir sua argumentação ou comprovar ponto de vista, é possível perceber o ethos de identificação em muitas postagens, que se destinam a alcançar o maior número possível de pessoas que acompanham a página.

Alguns subtipos se destacaram nesta categoria geral, entre eles o ethos de humanidade, que resulta da capacidade do ser humano em demonstrar seus sentimentos.

1) Mas, gente, se nós fomos educadas a viver com medo, como faz? Medo de não conseguir um trabalho, medo de não conseguir estabilidade, medo de homem, medo de mulher, medo de ficar solteira, medo de casar, medo de ser rejeitada, medo de os peitos caírem, medo de a bunda cair, medo de ficar magra, medo de ficar gorda, medo de ser inteligente, medo de ser ignorante... medo, medo, medo de tudo. (LUNA, Juliana. Autocuidado: como reprogramar uma mente educada a viver com medo?, AzMina, 03 de outubro de 2017).

O ethos de humanidade se manifesta em diversas esferas das relações sociais e pode contribuir para a construção de uma imagem positiva ou negativa. Sendo assim, o auditório decidirá se os sentimentos manifestados estão ou não de acordo com a figura que o enunciador deseja projetar.

É interessante analisar que, embora elas discorram sobre experiências individuais, os excertos analisados nos apresentam a maneira pela qual a mulher sofre forte pressão social em relação ao corpo e as consequências para ela, enquanto alguém que se vê identificada como objeto simbólico e "tem por efeito colocá-las em permanente estado de insegurança corporal, ou melhor, de dependência simbólica: elas existem primeiro pelo, e para o olhar dos outros, ou seja, enquanto objetos receptivos, atraentes disponíveis" (BOURDIEU, 2012, p. 82). Dessa forma, a grande mídia, a indústria da moda e da beleza se apoderam desse pensamento que valoriza o estético para enriquecerse e, consequentemente, colabora com a propagação desse corpo ideal, que, na maioria das vezes, se apoiam em padrões inalcançáveis de beleza.

O que predomina nos textos do Não me Kahlo e é habitual em grande parte das publicações na Revista AzMina é a utilização de estratégias discursivas de denúncia, principalmente da estrutura que é imposta, que gera muita violência, preconceito e desigualdades. Os/as colaboradores/as se revelam comprometidos com suas convicções, e dessa forma, deixam transparecer as crenças e valores pelos quais acreditam.

2) O que eu digo para essa mãe que, durante sua infância, foi doutrinada a pensar no casamento e na maternidade como prêmios e que, no alto de seus vinte e poucos anos, quando não menos, conseguiu esses prêmios e passou a precisar fazer o que fosse preciso para mantê-los, custasse a violência que custasse? (CARRILHO, Iara G. A mãe da minha amiga, Não me Kahlo, 07 de julho de 2017).

3) Nem sempre uma mulher tem direito à fala, quanto mais à escuta: nossa sociedade ainda cala e emudece nossas mulheres. (LEÃO, Bruna. Está cheio de ar: filme busca ouvir histórias de relacionamentos abusivos, Não me Kahlo, 10 de julho de 2017). 
A fim de preencher a lacuna da falta de visibilidade das mulheres como, por exemplo, nos argumentos de autoridade, os ambientes coletivos buscam em seus artigos vozes de outras mulheres, que ocupam cargos de reconhecimento e relevantes nas tomadas de decisões; ao mesmo tempo, AzMina e Não me Kahlo rompem com a ideia de que elas não detêm conhecimento nas tomadas de decisões públicas, atribuindo o ethos de inteligência a essas mulheres. As especialistas citadas colaboram na construção de uma nova realidade, na qual elas são agentes.

4) É o que diz a defensora pública de Ananindeua Luciana Guedes: "A grande maioria das mortes de mulheres aqui é resultado da violência. (...)" (AGÊNCIA PÚBLICA DE JORNALISMO INVESTIGATIVO, O poder público só nos vê quando a gente tomba, AzMina, 25 de outubro de 2017).

As autoras encontraram na escrita um meio de lutar contra as injustiças que denunciam, pois se utilizam do recurso de argumentos de autoridade, a fim de validar ainda mais seu discurso. As argumentações, ao serem construídas, se mostram embasadas ao trazer para os textos pesquisas, dados e números comprovando suas reivindicações. A urgência da mudança de cenário e ações que são cobradas revelam mulheres empoderadas que, ao adquirirem conhecimento, buscam uma nova realidade para elas e para aquelas que necessitam.

Na grande categoria de ethos de identificação, o ethos de solidariedade se projeta, construindo-se por meio da reciprocidade. Para Charaudeau (2013, p. 163), "A solidariedade caracteriza-se pela vontade de estar junto, de não se distinguir dos outros membros do grupo e, sobretudo, de unir-se a eles a partir do momento em que se encontram ameaçados". Em uma visão geral, as análises resultam em perfis solidários com as adversidades vivenciadas ou não, os quais reconhecem no outro aspectos presentes na sociedade, como fome, desemprego, abuso, violência, baixa escolaridade, racismo e, por isso, lutam pelos direitos de todos.

Entre as temáticas que mais se destacaram nas análises, percebemos que as plataformas digitais procuram mostrar e esclarecer os tipos de manifestações de violência (físicas, verbais, psicológicas, simbólicas) que perpassam nosso dia a dia de maneira naturalizada. As publicações recorrem aos/às especialistas que buscam esclarecer como funcionam leis que podem beneficiar aqueles/as que vivem em situação de conflito, apresentam auxílio através de divulgação de aplicativos e sites de denúncia e possuem informações como telefones úteis em momento de violência, entre outras formas de assistência. Esses canais auxiliam a construção de um pensamento mais crítico e o reconhecimento da violência em relação às situações que, aparentemente, são habituais.

Os/As autores/as buscam esclarecer como o sistema oprime o feminino, além de fazer pensar, refletir e reconhecer as formas como a violência se manifesta, com o intuito de que a conscientização auxilie na mudança de cenário e na diminuição dos números de agressões, muito recorrentes na contemporaneidade, especialmente se nos referirmos à violência doméstica, apresentando altos e crescentes índices.

5) Atualmente, no Brasil, a cada 7 minutos a polícia recebe pelo menos uma denúncia de violência doméstica, nas quais em $85,85 \%$ dos casos a agressão parte de alguém da própria família - sendo $58,55 \%$ das vítimas mulheres negras, $49,82 \%$ de abusos físicos e $30,40 \%$ de abusos psicológicos. O restante está dividido entre violência moral e sexual. 
(BARBOSA, Ana Luiza. Psicóloga Maria Clara Zamforlim responde sobre violência doméstica, Não me Kahlo, 25 de agosto de 2018).

Vale destacarmos que esse recorte pode também referir-se ao ethos de credibilidade. Para Fiorin (2015, p. 159), "os números dão uma aparência de objetividade à argumentação". Notamos que as autoras se valem dos recursos de tipo argumentos probabilísticos, ao apresentarem dados e porcentagem a fim de conferir credibilidade aos argumentos apresentados no decorrer dos artigos. Há, também, presença de argumentos baseada em fatos que, apontados nos dados, são consistentes, verdadeiros e objetivos, o que contribui para persuasão. Os argumentos apresentados são eficazes, pois discutem aquilo que emerge nos dados.

Os altos índices de violência doméstica têm sido pauta não somente nos blogs, mas em discussões que se mostram emergentes na atualidade. As análises apontam uma cultura sexista em que a mulher é objetificada; nesse sentido, seu corpo é compreendido como objeto que deve servir e satisfazer. Em consequência dessa falsa ideia, acompanhamos os altos e crescentes índices de estupros e violências. Essas agressões são reflexo da estrutura heteronormativa enraizada, compreendendo o ser mulher como submissa ao homem, identificando o masculino como superior ao feminino.

Uma forma de lutar contra as discriminações e desigualdades sexuais encontrada pelas autoras se faz notória através da recorrência dos verbos "resistir" e "lutar", frequentes nas publicações:

6) Todos os dias da presidência de Trump, nós resistiremos. Nós resistiremos ao racismo, à exploração capitalista, ao hétero patriarcado. Nós resistiremos ao preconceito contra o Islã, ao preconceito contra as pessoas com deficiência. Nós defenderemos o meio ambiente contra insistentes ataques predatórios do capital. (Transcrição da fala de Ângela Davis na Reitoria da Universidade Federal da Bahia no dia 25 de julho de 2017, Não me Kahlo, 11 de agosto de 2017).

7) "Precisamos do Dia da Consciência Negra pra nos apropriarmos do nosso poder enquanto maioria da população do Brasil e utilizamos pra dar um basta na bandalheira que estamos vivenciando em nosso país. Podemos dizer BASTA! por meio do nosso voto em 2018. Todos os partidos e candidatos que votaram a favor das medidas e projetos de reforma e mudanças que prejudicam a população negra devem ser riscados de nossa lista. (FOLEGO, Thais. "Nossa pele preta é o nosso manto de coragem e resistência", AzMina, 20 de novembro de 2017).

8) Poucas mulheres que ainda não são mães, sabem que existe uma força externa enorme para que não amamentemos. O sistema que nos empurra para o uso da fórmula (leite artificial) é ainda mais perverso do que o que nos empurra para a cesárea. (LEITE, Tainá. Escolhi amamentar meu filho no trabalho, mas isso ainda incomoda, AzMina, 02 de agosto de 2017, grifo da autora).

Os discursos são essenciais na mudança de uma estrutura estabelecida. As mulheres buscam ter voz nos lugares que eram reconhecidos por outros e para outros. "Por meio destas lutas, os sujeitos fazem circular discursos com interpretações de suas identidades e interesses políticos, que podem entrar em embate com a Ideologia dominante nas lutas de deslocamento ideológico." (CESTARI, 2015, p. 37-38).

Outra imagem que colabora para a construção do ethos de identificação é o ethos de competência que se manifesta na força, a apresentação de si por meio dos verbos 
relacionados ao campo semântico de guerra e batalha (lutar, resistir, defender) para mostrar que estão relutantes e persistentes na construção de uma nova realidade feminina. Os discursos resultam na construção do ethos de competência por meio do comportamento elocutivo e a escolha lexical.

As autoras se mostram sujeitos políticos conscientes de suas ações e do poder que elas têm. Elas recusam que as decisões sejam tomadas por outros no lugar delas. As plataformas on-line apresentam conflitos vividos por mulheres, como são/estão sendo enfrentados, por exemplo, o discurso da amamentação e a licença maternidade. Os sujeitos discursivos falam de suas experiências e se baseiam em experiências cotidianas com o intuito de ilustrar como o machismo estrutural se manifesta em diversas esferas sociais.

Um dos cenários apresentados pelas autoras em suas publicações refere-se à mulher negra estar submetida mais frequentemente a essas situações de violência ou a outros problemas que estão diretamente ligados à classe social, como menor grau de escolaridade e condições de vida mais precárias, neste caso, a mulher negra é duplamente discriminada. Podemos observar esses altos índices nos trechos a seguir:

9) Entre a população branca atendida, 9,5\% saem do serviço de saúde com a percepção de que foram discriminadas. O percentual sobe para $11,9 \%$ entre pretos e $11,9 \%$ pardos - a soma dos dois grupos representa a população negra, segundo a definição do IBGE. Elas também têm menos acesso a planos de saúde e a internações, consultam menos médicos e dentistas, têm mais dengue, são vítimas em maior proporção de acidentes de trânsito e trabalho e de violências e agressões. (...) (FOLEGO, Thais. Criminalização do aborto mata mais mulheres, AzMina, 28 de setembro de 2017).

10) Interpreto experiências racistas como estas do dia a dia como se algo estivesse tentando nos agredir dizendo: "este não é o seu lugar" ou "você é estranha aqui". Isso acontece sobretudo quando estamos em aviões, hotéis, universidades ou espaços conhecidamente elitizados, associados a um maior poder aquisitivo, onde os mais de cem milhões de mulheres e homens negros brasileiros ainda não estão proporcionalmente representados. (GÉNOT, Luana. Teste do pescoço: você já fez?, AzMina, 09 de agosto de 2017).

Em relação ao último excerto, o sentimento de não pertencer a certos lugares sociais é comum para pessoas de baixa condição financeira, e essa diferença é ressaltada se for negro ou pardo, pois há falta de representatividade nesses espaços privilegiados. Melo e Rocha (2015, p. 116) concluíram em sua pesquisa que "os corpos femininos morenos, mestiços, negro e infantis são construídos como ilegítimos". Essa afirmação coaduna-se com o excerto acima. A representatividade é reflexo de poder. Se o sujeito se reconhece representado em espaços privilegiados, ele compreende como lugar que pode ser alcançado. No entanto, a falta de representatividade permite constatar que determinados espaços sociais não lhe pertencem.

Desse encadeamento advém a desvalorização do negro, não somente em relação à cor, mas também à sua cultura, traços etc., além de discutir os estereótipos ligados ao negro, em que é associado à marginalização. Ainda, segundo Melo e Rocha (2015), na literatura e no cinema, o negro é representado como passivo, o seu ser objetificado, além de atribuições de características pejorativas. Os persistentes estereótipos são da mulata hipersexualizada, o negro malandro, moleque, pivete, escravo, mãe preta etc. Assim sendo, nossas análises demostram que as autoras, em suas áreas de atuação, buscam 
romper com os estereótipos perpetuados até os dias atuais, que impedem diferentes e positivos olhares ao negro na sociedade.

No blog e na revista os ethé são percebidos como coletividade que tem valores e saberes em comum. Elas buscam romper com identidades e representações que não acreditam ser única forma de existir, além de propiciarem novas possibilidades de performatividade. Assim sendo, as figuras maternas, de dona de casa e esposa, não ocupam lugar de destaque nas publicações. Os diversos ethé que se manifestaram nas análises comprovam a diversidade que permeia as mulheres. As análises demonstraram o poder e o valor das mulheres na coletividade, que em sua maioria se veem comprometidas com os problemas sociais. Foi possível observar fragmentos discursivos que apontam as características dos enunciadores militantes da causa feminista.

\section{CONSIDERAÇÕES FINAIS}

Por meio desta pesquisa, identificamos que nas plataformas analisadas, os perfis femininos proporcionaram um novo olhar em relação à mulher. Durante as análises, os ambientes coletivos dedicaram espaço a debater e discutir as diferenças sociais, resultando em representações de mulheres politicamente ativas e engajadas nas causas que circulam no ambiente público. As pautas presentes perpassaram diversos âmbitos e discutiram problemas resultantes de uma sociedade heteronormativa e preconceituosa, resultando em ambientes de apoio às mulheres, julgando o conhecimento e a informação como as melhores estratégias para que as situações relatadas não perpetuem.

Neste estudo, tornou-se mais transparente o relevante papel das mídias on-line nas causas nas quais os/as autores/as estão engajados/as: devido à rápida propagação (são plataformas on-line com um relevante número de seguidores), ao poder de convencimento por meio do discurso (a pesquisa apontou a presença de ethé de credibilidade) e a sua implicação nas relações sociais (pela capacidade das palavras se transformarem em ação, e as ações transformarem a realidade), e ainda, à capacidade de construção de posicionamentos identitários, que levam à captação dos/as leitores/as (a pesquisa destacou também a presença de ethé de identificação).

A principal forma de denunciar as desigualdades encontradas foi por meio da divulgação de notícias e relatos, que através de experiências reais buscaram refletir as diferentes formas de tratamento e oportunidades que permeiam os sujeitos na sociedade. Além disso, foi comum em todas as análises a desconstrução do padrão hegemônico de mulher passiva, pois ela se destaca no âmbito público e social, rompendo com a oposição estereotipada que cerca as relações sexuais - homem/mulher, privado/público, poder/submissão - .

No entanto, sabemos por meio dos ethé resultantes das análises que o cenário apresentado ainda não é comum para toda a sociedade. Por mais que a busca pela construção de novas realidades já esteja acontecendo, há um longo caminho a ser percorrido para alcançarmos a igualdade. Durante o período da pesquisa, observamos a relevante incidência de notícias no nosso dia a dia relacionadas ao racismo, violência doméstica e altos índices de feminicídio, que nos aponta para uma realidade de 
desrespeito à mulher, ocasionando a dificuldade de atualização dos dados devido à significativa recorrência desses problemas.

\section{REFERÊNCIAS}

AMOSSY, Ruth. Imagens de si no discurso: a construção do ethos. $2^{\text {a }}$ ed. São Paulo: Contexto, 2018.

BEAUVOIR, Simone de. O segundo sexo: fatos e mitos. Trad. Sérgio Milliet. $3^{\text {a }}$ ed. Rio de Janeiro: Nova Fronteira, 2016.

BRANDÃO, Helena H. Nagamine. Introdução à análise do discurso. $2^{\mathrm{a}}$ ed. rev. Campinas, SP: Editora da Unicamp, 2014.

BOURDIEU, Pierre. A dominação masculina. $11^{\mathrm{a}}$ ed. Rio de Janeiro: Bertrand Brasil, 2012.

CASTELLS, Manuel. Redes de indignação e esperança: movimentos sociais na era da internet. Trad. Carlos Alberto Medeiros. 2a ed. Rio de Janeiro: Zahar, 2017.

CASTRO, Ana Lúcia; PRADO, Juliana do. Corpo e identidades femininas: a intermediação da mídia. Estud. sociol., Araraquara, v.17, n.32, p. 241-259, 2012.

CESTARI, Mariana Jafet. Vozes-mulheres negras ou feministas e antirracistas graças às Yabás. 2015. 264 f. Tese (Doutorado em Linguística) - Instituto de Estudos da Linguagem, Universidade Estadual de Campinas, Campinas.

CHARAUDEAU, Patrick. Discurso Político. Trad. Dilson Ferreira da Cruz e Fabiana Komesu. 2 ed., $1^{\text {a }}$ reimpressão. São Paulo: Contexto, 2013.

CHARAUDEAU, Patrick. A conquista da opinião pública: como o discurso manipula as escolhas políticas. Trad. Angela M. S. Corrêa. São Paulo: Contexto, 2016.

CHAVES, Luís de Gonzaga Mendes. Minorias e seu estudo no Brasil. Revista de Ciências Sociais, Fortaleza, v. 1, n. 1, p. 149-168, 1970. Disponível em < http://www.rcs.ufc.br/edicoes/v2n1/rcs_v2n1a8.pdf>; acesso em 20 de mai. 2020.

DIAS, Cristiane Pereira. Mídia, circulação e discurso. In: Marta Mourão Kanashiro; Daniela Tonelli Manica. (Org.). Ciências, culturas e tecnologias: divulgações plurais.

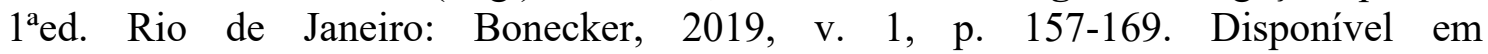
$<$ http://www.labjor.unicamp. br/wp-content/uploads/2019/05/CienciasCulturasETecnolo gias.pdf $>$; acesso em 20 de mai. 2020.

FIORIN, José Luis. Os fatores da argumentação. In: Argumentação. São Paulo: Contexto, 2015.

GIDDENS, A. The Constituion of Society. Outline of the Theory of Structuration. Cambridge: Polity Press, 1984 (2003)

MELO, Glenda C. V.; ROCHA, Luciana Lins. Linguagem como performance: Discursos que também ferem. Coleção Mestrado em Linguística. Discursos: sentido e Ação, 2015. Disponível em <https:/www.academia.edu/28892900/LINGUAGEM COMO_PERFORMANCE_DISCURSOS_QUE_TAMB\%C3\%89M_FEREM $>$; acesso em: 01 de mar. 2019. p. 101-119.

SOUZA, Daniela Márcia de, M.Sc., Universidade Federal de Viçosa, fevereiro de 2017. "Mais que uma menina que se veste de menino" - Uma análise discursivo-crítica das representações de Tereza Brant. Orientadora: Maria Carmen Aires Gomes. 
Artigo recebido em: mar. de 2020.

Aprovado e revisado em: mai. de 2020.

Publicado em: julho de 2020.

Para citar este texto:

SOUZA, Nayara Iris Silva e; MENDES, Paulo Henrique Aguiar. Representações de Si nos Discursos Feministas em Práticas Midiáticas Digitais Coletivas: Não me Kahlo e AzMina. Entremeios [Revista de Estudos do Discurso, ISSN 2179-3514, on-line, www.entremeios.inf.br], Seção Estudos, Programa de Pós-Graduação em Ciências da Linguagem (PPGCL), Universidade do Vale do Sapucaí (UNIVÁS), Pouso Alegre (MG), vol. 21, p. 194-210, jan. - jun. 2020.

DOI: http://dx.doi.org/10.20337/ISSN2179-3514revistaENTREMEIOSvol21pagina194a210 